\title{
Ação de informação para cidadania: biblioteca e arquivo escolar
}

Isa Maria Freire

Doutora em Ciência da Informação - Universidade Federal da Paraíba (UFPB/DCI)

Nanci Gonçalves da Nóbrega

Doutora em Ciência da Informação - Universidade Federal Fluminense (UFPB/DCI)

Sandra Borges Badini
Mestre em Biblioteconomia - Universidade Federal Fluminense (UFPB/DCI)

Vânia Maria Rodrigues Hermes de Araújo

Doutora em Ciência da Informação - Museu de Astronomia e Ciências Afins (MCT/MAST)

Apresenta resultados de um projeto desenvolvido pelo Grupo de Pesquisa Informação e Inclusão Social do IBICT em parceria com o Departamento de Ciência da Informação da Universidade Federal Fluminense (UFF). Descreve a ação realizada na disciplina Temas especiais: Informação para cidadania, oferecida nos cursos de graduação em Arquivologia e em Biblioteconomia. Destaca como resultados: o diagnóstico dos recursos de informação do Colégio Universitário da UFF, em Niterói, $R J$; a proposição, pelo curso de Biblioteconomia, de um projeto de extensão para apoio técnico ao melhoramento dos recursos da biblioteca do Colégio Universitário da UFF; a conscientização dos alunos sobre a importância do arquivo e da biblioteca escolar.

Palavras-chave:Ciência da Informação; Responsabilidade social; Cidadania; Acesso livre à informação; Arquivo escolar; Biblioteca escolar. 


\title{
An information action for citizenship:school library and archive
}

\begin{abstract}
The articles presents results from a research project developed by the Research Group on Information and Social Inclusion of the Brazilian Institute of Information in Science and Technology (IBICT), together with the Department of Information Science of Universidade Federal UFF). It describes the actions that have been carried out with Library Science and Archivology students in 2006. Some of the important results are: diagnosis of the information resources of Colegio Universitario of UFF, in the city of Niteroi; proposal, by the UFF Library Science Course, of an Extension project on management of information resources to be offered to the technical support staff of Colegio Universitario; and, development of student awareness about the importance of school library and archives.
\end{abstract}

Keywords:Information Science; Social Responsibility; Citizenship; Open Access to Information; School Library; School Archive.

Recebido em 02.01.2008 Aceito em 02.03.2009

\section{Introdução}

Neste artigo apresentamos o processo e o resultado do projeto Ação para Cidadania e Acesso Livre à Informação, que desenvolvemos na Universidade Federal Fluminense (UFF) com a colaboração de alunos dos cursos de Biblioteconomia e de Arquivologia, com vistas ao diagnóstico dos recursos de informação do Colégio Universitário da UFF, na da cidade de Niterói, RJ.

Nosso projeto teve como premissa a responsabilidade social da Ciência da Informação, apresentando caráter participativo tanto em nível institucional (por se tratar de parceria entre pesquisadores de instituições diferentes) quanto em nível operacional (por associar ensino e pesquisa em uma mesma atividade).

Com o presente texto, esperamos contribuir para ampliar a discussão sobre o valor dos arquivos e das bibliotecas escolares como fontes de informação na sociedade contemporânea, bem como propiciar aos docentes e alunos das áreas de Arquivologia e Biblioteconomia um modelo de ação de informação onde ensino e pesquisa resultem em exercício da cidadania, mediante serviços à comunidade. 


\section{Sobre a ciência e as ações de informação}

A Ciência da Informação surgiu em um contexto histórico em que a grande preocupação era organizar o enorme volume de informação produzida e disponibilizá-la, utilizando os mecanismos e tecnologias acessíveis na época. Era necessário gerenciar e controlar o grande volume de informação, estocar e caracterizar seu conteúdo, bem como priorizar o seu uso de acordo com as diferentes comunidades informacionais. Nessa perspectiva, a Ciência da Informação teria surgido...

[...] não por causa de um fenômeno específico que existia antes e que veio a se tornar seu objeto de estudo, mas [pela] necessidade de abordar um problema que mudara completamente a sua relevância para a sociedade (WERSIG; NEVELLING, 1975 citados por FREIRE, 1995, p.133).

As primeiras pesquisas desta disciplina priorizavam a recuperação da informação, o que tornou possível o desenvolvimento de inúmeras aplicações em produtos, sistemas, redes e serviços de informação. Na década de 1970, o tema da recuperação da informação começou a abranger os processos de comunicação humana em si, passando a considerar os usuários da informação e suas interações e a ser visto como um campo de "estudo do modo pelo qual as pessoas, criam, usam e comunicam informações" (SARACEVIC, 1996, p.48). Recentemente, no início do século XXI, González de Gómez (2003, p. 61) entende a Ciência da Informação como...

Aquela que estuda fenômenos, processos, construções, sistemas, redes e artefatos de informação, enquanto 'informação' for definida por ações de informação as quais remetem aos atores que as agenciam aos contextos e situações em que acontecem e aos regimes de informação em que se inscrevem (Grifo nosso).

Nessa perspectiva, a autora propõe que

[...] as ações de pesquisa e as ações de informação integrarão um mesmo domínio de orientações estratégicas e, em conseqüência, a política e gestão da Informação formarão parte do mesmo plano decisional e prospectivo ao qual pertence a política e gestão da ciência e da tecnologia - agora reunidos em um só paradigma epistêmico-administrativo (GONZÁLEZ DE GÓMEZ, 2003, p. 64, grifos nossos). 
Neste modelo, Ação de Informação refere-se a um conjunto de "estratos heterogêneos e articulados, que se manifestam através de três modalidades" (GONZÁLEZ DE GÓMEZ, 2003, p. 64):

a) ação de mediação: quando a ação fica atrelada aos fins e orientação de uma outra ação;

b) ação formativa: quando a ação está orientada à informação não como um meio, mas como sua finalização;

c) ação relacional: quando a ação busca intervir em uma outra ação para obter direção e fins.

Destarte, conforme proposto por González de Gómez (2004, p.58), uma "ação de informação" não estaria restrita às "ações formalizadas e instrumentalizadas por um sistema de informação, [podendo-se aplicar o conceito] a diferentes modalidades de ações". A nosso ver, o conceito se aplica à ação cujos resultados estamos relatando, a qual pode ser vista como um 'dispositivo de informação', conceito usado pela autora para se referir a "tudo aquilo que disponibiliza e deixa disponível, como mediação das mediações, um valor de informação" (GONZÁLEZ DE GÓMEZ, 2004 p.62). Criar este valor no coração e nas mentes dos sujeitos desta ação para a cidadania foi o propósito da nossa ação de informação.

\section{Quanto aos objetivos e procedimentos}

Rodrigues (2003, p.369) assinala que "há várias formas de trabalhar a articulação entre ensino e pesquisa nos cursos de graduação", sendo uma delas tomar a pesquisa como um "eixo" do ensino, traduzindo-se na possibilidade de disciplinas onde as atividades sejam planejadas coletivamente "com o objetivo de desenvolver habilidades e atitudes de investigação nos alunos". Nossa proposta se aproxima desta perspectiva, podendo ser caracterizada, ao mesmo tempo, como uma ação relacional, quando buscamos intervir no espaço educacional, e como ação formativa, enquanto disciplina no âmbito de uma instituição de ensino superior.

Assim, o projeto Ação para Cidadania e Acesso Livre à Informação foi desenvolvido no escopo da disciplina eletiva Temas especiais: Informação para cidadania, com 60h/aula e representando quatro créditos nos currículos de Biblioteconomia e de Arquivologia. Dos 11 alunos que participaram desta pesquisa/ação de informação, seis eram alunos de Arquivologia ${ }^{1}$ e cinco de Biblioteconomia ${ }^{2}$.

Nossos objetivos com o projeto Ação para Cidadania e Acesso Livre à Informação, foram:

1 Alunos de Biblioteconomia: Aline Barreto, Ana Gawryszewski, Joel Prata, Tatiana Felix e Thiago da Cunha de Oliveira.

2 Alunos de Arquivologia: Bianca Dias Mendes, Daianne dos Santos, Danuta Pullig, Leonardo Santos de Almeida, Paula Fernanda Ferreira e Samyra Silos dos Santos. 
a) propiciar aos alunos oportunidades para realizar uma ação de informação;

b) promover a troca produtiva de conhecimentos e experiências entre pesquisadores do Grupo Informação e Inclusão Social e professores e alunos dos cursos de Biblioteconomia e Arquivologia da UFF.

A escola que constituiu o campo empírico da pesquisa foi o antigo CIEP Professor Geraldo Achilles do Rosário Reis, no Bairro de São Domingos, em Niterói, que vem funcionando como Colégio Universitário Geraldo Reis desde abril de 2006, a partir de um convênio entre a UFF e a Secretaria Municipal de Educação.

Iniciamos as atividades na disciplina-pesquisa com uma discussão sobre a responsabilidade social dos profissionais da informação, notadamente no que diz respeito ao ensino fundamental, considerado de extrema relevância para o desenvolvimento sócio-cultural dos cidadãos na sociedade da informação. Depois de desenharmos o quadro de referência conceitual da pesquisa, foram formados dois grupos, um com alunos de Arquivologia e outro com alunos de Biblioteconomia, para elaborar, com apoio docente, os instrumentos da pesquisa de campo.

\section{Quadro de referência}

As abordagens e conceitos sobre biblioteca e arquivo escolar, aqui descritos, foram apresentados e discutidos em sala de aula, fundamentando a construção dos instrumentos de pesquisa para diagnóstico dos recursos de informação da escola.

\subsection{Biblioteca escolar}

Embora quase sempre esquecida, e muitas vezes marginalizada, como aponta Fragoso (2002), a biblioteca tem funções fundamentais a desempenhar na escola, agregadas em duas categorias: a educativa e a cultural. Segundo a autora, a educativa representa a motivação da busca do conhecimento, incrementando a leitura e ainda auxiliando na formação de hábitos e atitudes de manuseio, consulta e utilização do livro, da biblioteca e da informação. Nesse sentido, o papel educativo da biblioteca é o de complementar as informações básicas dos conteúdos programáticos e oferecer seus recursos e serviços à comunidade escolar de modo a atender as necessidades do planejamento curricular.

A essas funções, Caldin e Fleck (2003/2004, p.155) acrescentam a função técnica, considerando que a biblioteca escolar

Deve favorecer a consecução de todos os objetivos educacionais: 
transversalidade, acesso à cultura e, especialmente, ao fomento da leitura. Para tanto, precisa desempenhar funções educativas, culturais e técnicas.

$[\ldots]$

Seriam funções educativas: o fomento da leitura; o fomento da pesquisa; o desenvolvimento da criatividade; a educação para o lazer; a informação e orientação para a vida.

$[\ldots]$

Seriam funções culturais: promover, de forma interdisciplinar, diversas atividades culturais no espaço da biblioteca como exposições, concursos literários, saraus literários, feiras de ciências, entre outras; proporcionar informação sobre as atividades culturais externas à escola.

$[\ldots]$

Seriam funções técnicas: gerenciar e organizar os recursos informacionais; explorar esses recursos e difundi-los à comunidade escolar; facilitar 0 acesso a esses recursos (CALDIN; FLECK, 2003/2004, p.155).

A função educativa da biblioteca escolar representa um reforço à ação do aluno e do professor. Já em relação ao aluno, as atividades da biblioteca podem ajudar a desenvolver habilidades de estudo independentes, ou atuar como instrumento de auto-educação na busca pelo conhecimento, ou, especialmente, desenvolver sua leitura e auxiliar na formação de hábitos e atitudes de manuseio, consulta e utilização do livro, da biblioteca e da informação. Enfim,...

[...] a biblioteca escolar é um centro ativo de aprendizagem. Nunca deve ser vista como mero apêndice das unidades escolares, mas como núcleo ligado ao pedagógico. 0 bibliotecário trabalha com os educadores e não apenas para eles ou deles isolados. Integrada à comunidade escolar, a biblioteca proporcionará a seu público leitor uma convivência harmoniosa com o mundo das idéias e da informação (FRAGOSO, 2002, p.124).

Considerando esse quadro de referência, foi desenvolvido um instrumento de pesquisa para orientar as observações do grupo de alunos de Biblioteconomia durante as visitas ao campo de pesquisa, de modo a identificar:

a) A existência [ou não] de cooperação entre biblioteca e escola no atendimento às necessidades de informação dos alunos, professores e demais integrantes da comunidade escolar; 
b) A existência [ou não] de mecanismos de estímulo e orientação à comunidade escolar em suas consultas e leituras;

c) Se a biblioteca (i) proporciona aos usuários materiais diversos e serviços adequados ao seu aperfeiçoamento e desenvolvimento individual e coletivo; (ii) oferece mecanismos para a democratização da informação, permitindo o acesso da comunidade extra-escolar a materiais educativos do seu acervo; (iii) contribui para o acesso, dos professores e servidores, a fontes de informação para atualização técnica e de conteúdos;

d) Se o acervo está organizado a partir de técnicas bibliotecárias: (i) se há processamento técnico dos documentos [registro, representação temática e descritiva, indexação, ficha de leitura, etiquetagem]; (ii) se há processamento do uso [cadastro de usuários, controle de empréstimos].

\subsection{Arquivo Escolar}

O Novo Dicionário Aurélio (2004) define "arquivo" como:

1. Conjunto de documentos manuscritos, gráficos, fotográficos, etc., recebidos ou produzidos oficialmente por uma entidade ou por seus funcionários, e destinados a permanecer sob a custódia dessa entidade ou de seus funcionários. 2. Lugar onde se recolhem e guardam esses documentos [...]. (NOVO DICIONÁRIO AURÉLIO, 2004)

Já a Wikipedia apresenta uma abordagem mais técnica, definindo arquivo como o:

[...] conjunto de documentos criados ou recebidos por uma organização, firma ou indivíduo, que os mantém ordenadamente como fonte de informação para a execução de suas atividades. Os documentos preservados pelo arquivo podem ser de vários tipos e em vários suportes. As entidades mantenedoras de arquivos podem ser públicas (Federal, Estadual Distrital, Municipal), institucionais, comerciais e pessoais (ARQUIVO, 2006).

Nesse contexto, Vasconcellos (1999, p. 42) caracteriza o arquivo escolar como o "conjunto de documentos organicamente acumulados, cujas informações permitem a trajetória de vida de seu titular". Bonato (2002, p.3), por sua vez, esclarece que os arquivos escolares constituem acervos arquivísticos, contendo diversas espécies documentais que são fontes de pesquisa: "São espaços de memória, depositários de fontes produzidas e acumuladas na trajetória do fazer pensar o pedagógico no cotidiano das escolas". Contudo, segundo Ludke e André (1986, p.40), não existe uma preocupação das escolas em manter e preservar seus registros documentais: 
Em geral as escolas não mantêm registro de suas atividades, das experiências feitas e dos resultados obtidos. Quando existe algum material escrito, ele é esparso e conseqüentemente pouco representativo do que se passa no seu cotidiano. É evidente que esse fato também é um dado do contexto escolar e deve ser levado em conta quando se procura estudá-lo.

Solis (1992, p.55) destaca que, em geral, o espaço destinado à documentação acumulada pela escola é identificado como "arquivo morto", denominação que sugere uma documentação sem utilidade, "apenas uma massa de papel velho ocupando espaço, podendo ser descartável". Vidal (2000) alerta que, ao descartar a documentação de professores e alunos, joga-se fora uma possibilidade de estudar o cotidiano das escolas, ainda mais que a intenção da preservação dessa documentação é de caráter probatório, sendo necessária para a emissão de um certificado de conclusão de determinado período ou série. Nesse contexto, Menezes, Silva e Teixeira Junior (2005, p.75) ressaltam que os arquivos escolares são espaços com poucos investimentos de preservação e que sofrem com a eliminação indiscriminada dos documentos:

[Aos] fatores como a falta de uma política arquivística específica na área educacional, com funções claras, falta de pessoal capacitado, e dificuldades quanto ao local para a guarda do acervo documental, acrescentam-se ainda problemas relacionados aos procedimentos práticos e rotineiros de um arquivo, como tratamento, descrição, divulgação e condições de acesso aos documentos para os pesquisadores.

Considerando esse quadro de referência, foi desenvolvido um instrumento de pesquisa para orientar as observações do grupo de alunos de Arquivologia durante as visitas ao campo da pesquisa, de modo a identificar:

a) A função do arquivo do Colégio Universitário/UFF [memória, fins administrativos, as duas possibilidades];

b) Como o arquivo está organizado:

No tempo [desde quando];

No espaço [no mesmo local, em locais diferentes];

c) Os tipos de documentos que constituem o acervo:

Histórico escolar dos alunos;

Programas de disciplinas;

Cadastro de professores e outros servidores;

Documentos administrativos;

Outros. 
d) A utilização de critérios de separação entre documentos [organização, identificação];

e) O estado físico dos documentos [descarte];

f) O armazenamento dos documentos [possibilidade de consulta];

g) A disponibilidade de local para a realização do trabalho arquivístico;

h) A existência [ou não] de profissional arquivista [ou estagiário].

Depois de elaborados os respectivos protocolos de pesquisa sobre as atividades bibliotecárias e arquivísticas no Colégio Universitário/UFF, produzimos um roteiro de entrevista com questões a serem formuladas nas entrevistas com o diretor, funcionários e professores, durante a pesquisa de campo:

Com a Direção do Colégio Universitário/UFF:

- a Direção considera relevante e necessário o tratamento adequado [organização para consulta] do acervo bibliográfico/documentação arquivística?

- existem planos para organização adequada da biblioteca/do arquivo [espaço, acervo, pessoal]?

Com o pessoal do arquivo [professores, servidores]:

- consideram relevante e necessário o tratamento adequado [organização para consulta] do acervo bibliográfico/da documentação arquivística?

- possuem algum tipo de capacitação para a atividade bibliotecária/arquivística?

- quais os problemas mais comuns [nas atividades]?

Sob supervisão docente, os grupos de alunos agendaram e fizeram visitas ao campo da pesquisa com a finalidade de observar os recursos arquivísticos e biblioteconômicos, bem como de entrevistar o diretor, funcionários e professores do Colégio Universitário/UFF.

Ao final das atividades de observação e coleta de dados no campo da pesquisa, realizamos um fórum no qual foram apresentados e discutidos os resultados da experiência de cada grupo, bem como sugestões que possam subsidiar um modelo de atuação para profissionais de informação em unidades do ensino fundamental. O relatório final de cada grupo foi entregue ao Diretor do Colégio Universitário da UFF.

\section{Resultados da pesquisa de campo}

Os relatórios com os resultados da observação direta e das entrevistas realizadas pelos grupos, discutidos em sala de aula, demonstram o nível de conscientização ${ }^{3}$ dos alunos sobre os temas

Aqui entendida como "um processo que permite ao [ser humano] compreender a realidade que o cerca, como ela se estrutura, [...] e a reagir a essa realidade, assumindo seu destino e [o] dos seus semelhantes com autonomia, buscando sempre melhores condições de vida" (ROCHA, 2000 p.43). 
"biblioteca escolar" e "arquivo escolar". Os respectivos textos foram editados, para fins deste artigo:

\subsection{Relatório sobre a Biblioteca Escolar}

A seguir, apresentamos o relatório da pesquisa de campo realizada pelos alunos:

A instituição, juntamente com sua Biblioteca foi inaugurada no dia 8 de julho de 1986. Conforme as idéias propostas pela disciplina, tivemos o cuidado de visitar a instituição três vezes, quando fizemos as observações e entrevistamos Sérgio Aboud, Diretor do Colégio Universitário da UFF, a Bibliotecária Cristiane Gleich e a funcionária da escola que trabalha na biblioteca, Verônica Maria. O que podemos constatar através deles foi que ainda falta muita coisa para a escola e a biblioteca exercerem seus papéis transformadores. Antes da administração atual, o descaso era total com o material bibliográfico que dava entrada na biblioteca, algo que com a transferência da escola para a UFF já está mudando. Mas a biblioteca propriamente dita ainda sofre de carências.

Segundo Cristiane e a Verônica, anteriormente houve investimento na biblioteca. O acervo didático era atualizado e havia uma tentativa de classificação e catalogação. Mas com a mudança dos governos (a unidade estava vinculada ao Estado do Rio de Janeiro como CIEP, depois foi municipalizada), este esboço de uma biblioteca, efetivamente comprometida com os alunos e a comunidade, se extinguiu. Os problemas na biblioteca são inúmeros: falta ventilação, a iluminação é precária, o posicionamento das estantes não é o ideal, pois elas ficam encostadas na parede, o que causa infiltração. A Cristiane, que é graduada em Biblioteconomia pela UFF, nos falou da urgência de ter um computador e uma sala à parte, para colocá-lo em operação.

Para finalizar temos que registrar que todos, sem exceção, nos falaram de suas esperanças de dias melhores com a administração da UFF. Eles esperam que agora ocorra, efetivamente, uma transformação da Escola e, também, da Biblioteca. (BARRETO et al., 2006, passim)

\subsection{Relatório sobre o Arquivo Escolar}

A seguir, apresentamos o relatório da pesquisa de campo realizada pelos alunos: 
O relatório do grupo da Arquivologia foi elaborado a partir das observações e de duas entrevistas, que ajudaram na formulação do nosso relatório sobre o arquivo escolar. As entrevistas foram realizadas no Colégio de Aplicação da Universidade Federal Fluminense (Colégio Universitário da UFF), que funciona no antigo CIEP localizado próximo ao campus da universidade, com o diretor, professor Sérgio Aboud, e com a funcionária Rosele.

A entrevista com o diretor do Colégio Universitário da UFF nos possibilitou conhecer melhor o objetivo do projeto, desde o seu início até os dias atuais. Em 2005, após aprovação pela UFF, formou-se um grupo de trabalho dando início ao Colégio de Aplicação. O terreno pertence às Barcas S.A., porém o CIEP pertence à UFF. Os alunos do CIEP agora fazem parte do Colégio Universitário da UFF. Os professores da Universidade foram cedidos por um período de cinco anos. Atualmente 0 Colégio conta com alunos do C.A à $4^{\circ}$ série do ensino fundamental. Em 2007 contemplará desde o C.A até a $5^{\circ}$ série e em 2008 até a $6^{\circ}$ série.

$\mathrm{O}$ arquivo permanente do colégio fica localizado no $2^{\circ}$ andar do prédio, ao lado da copa, bebedouros e dos sanitários masculino e feminino, mas o local não tem problemas com umidade (pelo menos aparentemente), e, embora pequeno, conta com uma janela. Pudemos observar uma grande concentração de poeira no local, além de materiais de teatro e bacias de alumínio. A documentação está uma parte armazenada em caixas de papelão, aparentando acumular diversos tipos de bactérias, e não seria aconselhável manuseála sem a utilização de luvas e máscaras (o que provavelmente não acontece).

Outra parte da documentação está armazenada em pastas plásticas, que praticamente se esfarelam quando são tocadas. Entre a documentação identificada constavam boletins de ocorrência, declarações, circulares, relações de turmas, relatórios de professores, fichas de alunos, documentos de 1987 junto com jornais, lista telefônica, além de objetos de cozinha, como panelas etc. Essa documentação, pelo que observamos está acondicionada sem critérios de organização e conservação, e algumas caixas não estão identificadas. O local é fechado e sem circulação de ar. Estas características foram as que mais nos chamaram a atenção neste espaço reservado para a acomodação do 'arquivo permanente'. 
Contudo, ficou claro, nas entrevistas, que há uma preocupação da administração e dos funcionários para com a organização dos documentos. Percebemos que há interesse da Direção em realizar um bom serviço de arquivo, mas acreditamos que falta informação técnica (como fazer) e apoio de profissional arquivista, para que o trabalho seja realizado de uma forma mais adequada. (MENDES et al., 2006, passim)

\section{Resultados da ação de informação}

A observação das condições do arquivo e da biblioteca escolar no campo da pesquisa evidenciou a precária situação de ambos, no espaço do Colégio Universitário da UFF. De certa forma, a literatura já havia nos preparado para o que observamos, pois em que pese a relevância e importância da biblioteca, sabemos que a maioria das escolas não possui este equipamento, sendo a situação no arquivo permanente não menos preocupante.

Destarte, esperamos ter alcançado os objetivos propostos para o projeto Ação para Cidadania e Acesso Livre à Informação, que, embora se caracterize como pesquisa exploratória, apresentou resultados promissores, tanto na perspectiva da ação relacional quanto em relação à ação formativa:

a) O Colégio Universitário da UFF dispõe, agora, de um diagnóstico da Biblioteca e do Arquivo escolar, instrumentos de avaliação e planejamento que não existiam, sendo uma contribuição relevante para a gestão dos recursos de informação;

b) O curso de Biblioteconomia, em parceria com o curso de Arquivologia e com o Colégio Universitário da UFF, apresentou à Pró-Reitoria de Extensão da UFF o projeto Compartilhando Biblioteca e Cidadania, que tem como objetivo geral promover a "organização da Biblioteca do Colégio Universitário Geraldo Reis, e planejamento das ações de leitura, visando principalmente à consolidação do processo do ensino/aprendizagem e a inserção social dos alunos através da construção da cidadania tendo como pano de fundo as ações de leitura", a ser implementado a partir de 2007;

c) Os alunos de Biblioteconomia e Arquivologia tomaram contato e se conscientizaram das precárias condições para o funcionamento de bibliotecas e arquivos escolares, diametralmente opostas à relevância dos recursos de informação no apoio às atividades escolares.

Como os cursos de Biblioteconomia e Arquivologia, em geral, não contemplam disciplinas voltadas para Biblioteca e Arquivo Escolar em sua grade curricular, somos de opinião que uma ação de informação e 
cidadania, como esta empreendida junto ao Colégio Universitário da UFF, possibilita a docentes e alunos de Biblioteconomia e Arquivologia uma aproximação com as práticas desse campo de atuação profissional.

Esperamos que a idéia de uma ação de informação conduzida como apoio à organização de arquivos e bibliotecas escolares possa se espalhar e frutificar nas Escolas de Biblioteconomia brasileiras. Neste momento histórico, quando a educação básica começa a ser reconhecida como fundamento para um desenvolvimento econômico e social sustentável, podemos contribuir para resgatar o valor da Biblioteca e do Arquivo Escolar, colocando-os no lugar de destaque que merecem no regime de informação da sociedade da informação.

Esta pode ser uma das formas do exercício de responsabilidade social dos profissionais da informação, na área acadêmica: uma ação de informação pautada no exercício da cidadania, que possa contribuir para uma educação de qualidade na rede pública de ensino, de modo que mais e mais brasileiros possam conquistar a chance de uma vida melhor.

\section{Referências}

ARQUIVO. In: WIKIPEDIA. Disponível em: <www.wikipedia.org > Acesso em: 29 set. 2006 .

BARRETO, A. et al. Funções da biblioteca escolar e o papel do bibliotecário escolar. Niterói: UFF, DCI, 2006. Projeto Ação para Cidadania e Acesso Livre à Informação. [Relatório de pesquisa de campo.].

BONATO, N. M. C. Arquivos escolares: limites e possibilidades para a pesquisa. In: REUNIÃO ANUAL DA ANPED, 25., 2002, Caxambu - MG. Anais... Educação: manifestos, lutas e utopias. Rio de Janeiro: Anped,2002. p. 97-109. v. 1.

CALDIN, C. F.; FLECK, F. O. Organização de biblioteca em escola pública: - caso da escola de educação básica Dom Jaime de Barros Câmara. Revista $A C B$, v. 8/9, 2003/2004.

FRAGOSO, G. Biblioteca na escola. Revista $A C B$, v.7, n.1, 2002. Disponível em: <http://www.acbsc.org.br/revista/ojs/viewarticle.php?id=78>. Acesso em 9 set. 2006.

FREIRE, I. M. Informação; consciência possível; campo: um exercício com construtos teóricos. Ciência da Informação, Brasília, v. 24, n.1, 1995.

GONZÁLEZ DE GÓMEZ, M. N. Escopo e abrangência da Ciência da Informação e a Pós-Graduação na área: anotações para uma reflexão. Transinformação, v. 15, n. 1, p. 31-43, 2003.

Novas fronteiras tecnológicas das ações de informação: questões e abordagens. Ciência da Informação, v.33, n.1, p. 55-67, 2004. 
LÜDKE, M.; ANDRÉ, M. E. D. A. Pesquisa em educação: abordagens qualitativas. São Paulo: EPU, 1986. (Temas básicos de educação e ensino).

NOVO DICIONÁRIO AURÉLIO DA LÍNGUA PORTUGUESA. 3ed. São Paulo: Ed. Positivo, 2004. Versão eletrônica.

MENDES, B. D. et al. Comentário para o desenvolvimento da pesquisa na Escola de Aplicação da UFF a respeito do Arquivo escolar. Niterói: UFF: DCI, 2006. Projeto Ação para Cidadania e Acesso Livre à Informação. [Relatório de pesquisa de campo.].

MENEZES, M. C.; SILVA, E. C. L.; TEIXEIRA JUNIOR, O. O arquivo escolar: lugar da memória, lugar da história. Horizontes, v. 23, n. 1, p. 67-76, 2005.

ROCHA, M. P. C. A questão cidadania na sociedade da informação. Ci. Inf., Brasília, v. 29, n. 1, p. 40-45, jan./abr. 2000.

RODRIGUES, M. E. F. A pesquisa no ensino e o ensino da pesquisa. Transinformação, v.15, n.3, p.363-372, set./dez. 2003.

SARACEVIC, T. Ciência da Informação: origem, evolução e relações. Perspectivas em Ciência da Informação, v.1, n.1, p. 41-62, 1996.

SÓLIS, S. S. F. Documentos, fontes e arquivos. In: INSTITUTO BRASILEIRO DO PATRIMÔNIO CULTURAL. Memória e educação. Rio de Janeiro: IBPC, Departamento de Promoção, Paço Imperial, 1992. p. 5363. (Caderno de ensaios; 1 )

VASCONCELLOS, F. de. Lições de pedagogia experimental. Lisboa: Antiga Casa: Bertrand, 1999.

VIDAL, D. G. Fim do mundo do fim: avaliação, preservação e descarte documental. In: FARIA FILHO, L. M. (Org.). Arquivos, fontes e novas tecnologias: questões para a história da educação. Campinas, SP: Autores Associados; Bragança Paulista, SP: Universidade São Francisco, 2000. p.31-43. (Coleção memória da educação).

WERSIG, G.; NEVELING, U. The phenomena of interest to information science. The Information Scientist. v.9, n.4, p. 127-140, 1975. 